\title{
DERECHO DE EXCEPCIÓN Y CONTROL PARLAMENTARIO*
}

\author{
ANTONIO CIDONCHA MARTÍN \\ Profesor contratado doctor \\ Universidad Autónoma de Madrid
}

TRC, n. ${ }^{\circ} 48,2021$, pp. 433-462

ISSN 1139-5583

Sumario

I. Sobre el control parlamentario del Gobierno. II. Sobre el control parlamentario en nuestro Derecho de excepción. III. Sobre el control parlamentario y las alarmas decretadas en todo el territorio nacional para contener la pandemia. IV. Apuntes finales.

\section{SOBRE EL CONTROL PARLAMENTARIO DEL GOBIERNO}

\section{Una concepción de la función de control parlamentario del Gobierno}

Dice el TC (STC 124/2018, FJ 7) que la Constitución (CE en adelante) no define la función de control parlamentario del Gobierno (art. 66.1), sino que se limita a establecer determinados instrumentos de control en el título $\mathrm{V}$ (aunque — añado yo — no sólo en él), después regulados (y — añado yo- ampliados) en los reglamentos de las Cámaras. Dice también que es una función consustancial a la forma de gobierno parlamentaria y que su fundamento es el carácter representativo de las Cortes Generales.

Que la CE no defina el control parlamentario del Gobierno no significa, obviamente, que no pueda extraerse de ella esa definición. Definir esta función es algo que ha tenido muy entretenida a nuestra doctrina desde el siglo pasado (sobre todo en el

* El presente artículo se publica en el marco del acuerdo de colaboración firmado entre la Revista Teoría y Realidad Constitucional y el Centro de Estudios de Partidos de la UNED para la publicación de trabajos de investigación sobre partidos políticos. 
siglo pasado) ${ }^{1}$. Dado el limitado espacio del que dispongo, voy directamente al grano: me adscribo a la concepción amplia del control parlamentario que, en España, fue sustentada en el siglo pasado por Rubio Llorente ${ }^{2}$ y, muy especialmente, Aragón Reyes $^{3}$. Esta concepción amplia es la que, a la postre, ha acogido el Tribunal Constitucional — TC en adelante- (en la citada sentencia 124/2018, FJ 7)4.

Sigo al maestro Aragón Reyes y entresaco sintéticamente (casi a modo de titulares) los postulados básicos de su acabada teoría del control parlamentario:

Primero: el control parlamentario es un control políticos, que tiene por sujeto activo o «agente» al Parlamento y tiene por objeto «la acción del Gobierno y, por extensión, también la de cualesquiera entidades públicas, excepto las incluidas en la esfera del poder jurisdiccional» ${ }^{6}$.

Me atrevo a matizar al maestro, sirviéndome de otro maestro: «el ámbito de control —bien que éste sólo debe poder tener efectos sobre el Gobierno- no debe quedar constreñido, como su único objeto, a la actividad de los agentes públicos», puede extenderse a actividades de agentes privados, «habida cuenta de que allí residen con frecuencia los auténticos poderes cuyo comportamiento nos afecta a los ciudadanos» ${ }^{7}$.

Segundo: el control político del Gobierno es la función genuina del Parlamento, la que primordialmente debe cumplir ${ }^{8}$.

Es verdad que el Parlamento ejerce también la función legislativa (que, en sentido amplio, engloba también la presupuestaria), pero nadie sensato puede desconocer que la conexión Gobierno-mayoría parlamentaria hace que la ley responda hoy más a los designios del Gobierno que a los del Parlamento. Esto no es

1 Una relación de ellas, en FERNÁNDEZ SARASOla, I., «El control parlamentario y su regulación en el ordenamiento español», REDC, n. ${ }^{\circ}$ 60, 2000, pp. 94-96.

4 A lo que parece, esta concepción amplia es con la que se sienten más cómodos los politólogos. Vid. en este sentido Paniagua, J.L., «Los estudios sobre el Parlamento y el control parlamentario: una aproximación desde la ciencia política», en Tudela Aranda, J. (coord.), Los Parlamentos autonómicos en tiempos de crisis, Zaragoza: Fundación Manuel Giménez Abad de Estudios Parlamentarios y del Estado Autonómico, 2015, p. 92.

5 La diferencia entre control político, control jurídico y control social, en AraGón Reyes, M., Constitución y control del poder, ob. cit., pp. 143 y ss.

6 La cita, tomada de ARAGón REYEs, M., «Información parlamentaria y función de control», dentro de la obra colectiva Instrumentos de información de las Cámaras Parlamentarias, Madrid, CEPC, 1994, p. 23.

7 Garrorena Morales, A., "Algunas sugerencias para renovar la función de control», en PaU i VaLl, F. (coord.), Parlamento y control del Gobierno, Aranzadi Thomson Reuters, 1998, p. 434. Sobre la ampliación del control a todos los agentes implicados en la «gobernanza», vid. GonZÁLEZ FERNÁNDEZ, S., El control como función primordial en la era de la gobernanza, Zaragoza: Fundación Manuel Giménez Abad, 2020, pp. 196 y ss.

8 Causas harto conocidas han transformado el reparto de funciones políticas en los regímenes parlamentarios: si en el Estado liberal del XIX el Parlamento dirigía y el Gobierno ejecutaba las decisiones de aquél, en el Estado Social y Democrático actual, por el contrario, «el Gobierno dirige la política y el Parlamento la controla». Nuestra Constitución «lo reconoce expresamente al atribuir al Gobierno la función de «dirección política» (el Gobierno «dirige la política interior y exterior», art. $97 \mathrm{CE}$ ) y al Parlamento la función de control (las Cortes Generales «controlan la acción del Gobierno», art. 66.2 CE)» (ARAGón REYES, M., Estudios de Derecho Constitucional, ob. cit., p. 706). 
nada patológico sino, muy al contrario, un hecho congruente incluso con la propia CE, «pues al Gobierno le compete la dirección de la política y ello significa, sin duda, la dirección de la «política legislativa», puesto que es a través de ella como puede realizar su programa». Se comprende así que la función de control es, con toda seguridad, «la función más relevante que hoy cualifica al Parlamento del presente», pues «a través de ella puede la Cámara desempeñar un papel por sí misma sin la mediación gubernamental, esto es, apareciendo como institución distinta (e independiente) del Gobierno» ${ }^{9}$.

Conviene, no obstante, contextualizar la relevancia de la función de control, sobre la base del tipo de forma de gobierno parlamentaria por la que ha optado la CE: una forma de gobierno parlamentaria racionalizada. La racionalización se traduce, ex Constitutione, en la búsqueda de la estabilidad gubernamental y esta se localiza en la configuración de la moción de censura (arts. 113 y 114.2 CE). Para investir al Presidente del Gobierno basta la mayoría simple en el Congreso (art. $99 \mathrm{CE}$ ), pero para derribarlo y, con él, a su Gobierno, es preciso algo más: un candidato alternativo y mayoría absoluta en el Congreso. La CE ha diseñado un Gobierno con alta capacidad de resistir frente al Parlamento.

Tercero: la función de control parlamentario del Gobierno no se circunscribe a instrumentos o procedimientos determinados, sino que se desarrolla en todas las actuaciones parlamentarias ${ }^{10}$.

Existen, sin duda, instrumentos y procedimientos específicos de control parlamentario, pero no instrumentos exclusivos o propios, ya que la función de control tiene capacidad potencial para desplegarse en todas las actividades parlamentarias. Estamos ante lo que Aragón denomina «polivalencia funcional» del control parlamentario.

El TC participa plenamente de este entendimiento de la función de control parlamentario del Gobierno. Al igual que el profesor Aragón, nuestro Alto Tribunal sostiene que esa función «se desempeña, en la actualidad y en último término, a través de toda actividad parlamentaria» y, por tanto, se ejerce «no solo a través de los instrumentos que forman parte de la función de control, sino también a través de la función legislativa y de la función presupuestaria». Estamos, en palabras del TC, ante una «función poliédrica», «dirigida solo en último término a la ruptura de la confianza entre el Congreso y el Gobierno» (STC 124/2018, FJ 7).

9 Ibidem, p. 707.

10 «No sólo, pues, en las preguntas, interpelaciones, mociones, comisiones de investigación, control de normas legislativas del Gobierno [...] se realiza la función fiscalizadora, sino también en el procedimiento legislativo (crítica al proyecto presentado, defensa de enmiendas, etc.), en los actos de aprobación o autorización, de nombramiento o elección de personas y, en general en toda la actividad parlamentaria. En todos estos casos hay (o debe haber) debate y, en consecuencia, en todos hay (o puede haber) control parlamentario» (ARAGón Reyes, M., Estudios de Derecho Constitucional, ob. cit., p. 709). 
Cuarto: el significado actual del control parlamentario exige distinguir entre control por y control en el Parlamento.

Se trata de una distinción fundamental. El primero (control por el Parlamento) se manifiesta a través de decisiones de la Cámara, «que son siempre, inevitablemente, decisiones de la mayoría, porque así se forma la voluntad del Parlamento». El segundo (control en el Parlamento) se manifiesta «a través de actuaciones de los parlamentarios o de los grupos (preguntas, interpelaciones, intervención en debates ...)», esto es, a través de «la labor fiscalizadora del Gobierno, realizada, no por la mayoría, sino por la minoría». Ello es, «indudablemente, un modo de control parlamentario gracias a la publicidad y al debate que deben acompañar a los trabajos de la Cámara» ${ }^{11}$.

Manejaré esta distinción a lo largo del presente trabajo. Importa ahora determinar su base jurídico-constitucional:

a) En el control por el Parlamento se manifiestan las Cámaras como «órgano» contrapuesto al Gobierno; es, por tanto, un control «interorgánico».

Así está definido, ab initio, el control parlamentario en la CE. Para empezar, el artículo 66.2 CE atribuye la función de control de la acción del Gobierno a las «Cortes Generales». Por otra parte, los instrumentos específicos de fiscalización que menciona la CE están atribuidos a órganos: el artículo $76 \mathrm{CE}$ nos dice que las Comisiones de Investigación son nombradas por el «Congreso y el Senado y, en su caso, ambas Cámaras»; los artículos 109 y 110 CE remiten a las «Cámaras y sus Comisiones» las competencias de recabar información del Gobierno o de reclamar la presencia de miembros de éste; incluso las preguntas e interpelaciones no las formulan los diputados y senadores, sino que se formulan genéricamente «en las Cámaras» (art. $111 \mathrm{CE}$ ). Por último, la responsabilidad política es exigible ante el órgano «Congreso de los Diputados» (arts. 108 y 113 a $115 \mathrm{CE})$.

b) En el control en el Parlamento se manifiestan las Cámaras como «institución» que expresa el pluralismo político. Sus «titulares» son los parlamentarios, individualmente o a través de los grupos parlamentarios, los protagonistas reales de la vida parlamentaria.

Este tipo de control (el más relevante) tiene también su acomodo en la $\mathrm{CE}$, si bien de forma implícita. Puede deducirse del principio democrático (art. 1.1 CE), del que se deriva la exigencia de democracia interna en el seno de la institución representativa, lo que implica a su vez que deben respetarse los «derechos» de las minorías, tanto en la composición de sus órganos internos como en su funcionamiento cotidiano. Las minorías 
deben poder participar en las funciones de las Cámaras, singularmente en la función de control de la acción del Gobierno ${ }^{12}$.

Sin embargo, el control en el Parlamento tiene una garantía más concreta y efectiva que la que se deriva del principio democrático: el derecho fundamental del art. 23.2 CE, que, según la interpretación del TC, «garantiza no sólo el acceso igualitario a las funciones y cargos públicos, sino también que los que hayan accedido a los mismos se mantengan en ellos sin perturbaciones ilegítimas y los desempeñen de conformidad con lo que la ley disponga» ${ }^{13}$. El artículo $23.2 \mathrm{CE}$ incluye, pues, dentro de su contenido, el derecho a desempeñar el cargo representativo de conformidad con lo que la ley disponga, que podemos denominar también derecho al ejercicio del cargo público representativo (o derecho al ejercicio a secas).

No puedo detenerme en una delimitación jurisprudencial detallada de esta vertiente del derecho fundamental del artículo $23.2 \mathrm{CE}^{14}$. Baste decir aquí algo sobre su titular y sobre su contenido, de forma sumaria:

1) El titular del derecho fundamental al ejercicio del cargo parlamentario es el parlamentario individualmente considerado.

En verdad, en los reglamentos parlamentarios los derechos de los parlamentarios están en manos (de iure o de facto) de los grupos parlamentarios. Ello nos obliga a construir una ficción: distinguir entre titularidad y ejercicio de la función representativa. La titularidad es siempre individual (el parlamentario) pero el ejercicio puede ser individual (uti singuli) o colectivo $(u t i \text { socii })^{15}$, a través de los grupos parlamentarios en los que se agrupan los parlamentarios.

12 El TC es consciente de la eficacia jurídica del valor «pluralismo político», en cuanto proyectado sobre instituciones representativas, pues parte justamente del mismo para declarar que las decisiones de la mayoría no pueden ignorar los derechos de las minorías (STC 32/1985, FJ 2); o para decirnos, precisamente en sede de control parlamentario, que el respeto a las «atribuciones» de los miembros individuales del órgano parlamentario, o de los grupos o fracciones que estos formen, «deviene un imperativo constitucional en el marco de la democracia pluralista que la Constitución consagra en su artículo 1.1» (STC 161/1988, FJ 7).

13 STC 161/1988, FJ 6. Se trata de una doctrina consolidada. Véase, como resumen reciente, la STC $159 / 2019$, FJ 5.

14 Un análisis completo reciente en Cidoncha MARTín, A., «La defensa jurídica del estatus parlamentario en el ejercicio de la función de control del Gobierno», en Gutiérrez Gutiérrez, I. y SaLVAdor Martínez, M., División de poderes en el Estado de partidos, Madrid: Marcial Pons, pendiente de publicación. El trabajo actualiza un viejo trabajo del mismo autor [CidonCHA MARTín, A., «El control del Gobierno desde la perspectiva del parlamentario individual», en Aragón ReYes, M. y Gómez Montoro, A. (coords.), El Gobierno. Problemas constitucionales, Madrid: CEPC, 2005, pp. 339-406].

15 También hay derechos de ejercicio colectivo atribuido a un número X de parlamentarios (v.gr., el derecho a presentar proposiciones de ley — art. 126.1.1. ${ }^{\mathrm{a}} \mathrm{RCD}$-, a proponer mociones de censura — art. 175.2 RCD— o a proponer la convocatoria de plenos extraordinarios — art. 61.2 RCD—). Sobre la clasificación de los derechos-función de los parlamentarios, vid., Cidoncha MARTín, A., «El control del Gobierno desde la perspectiva del parlamentario individual», ob. cit., pp. 353 y ss. 
2) El contenido del derecho lo determinan los reglamentos parlamentarios. Estamos ante un derecho de configuración legal: corresponde a la ley, comprensiva de los reglamentos parlamentarios, determinar los «derechos» o «facultades» de los parlamentarios. Una vez determinados, quedan integrados en el status propio del cargo, de manera que sus titulares, al amparo del art 23.2 CE, podrán defender ante los órganos judiciales y, en último extremo, ante el TC, su ius in officium ${ }^{16}$.

Ahora bien — matiza el TC— no todos los «derechos» de los parlamentarios previstos en los reglamentos forman parte del ius in officium protegido por el art. 23.2 CE, tan solo aquellos que «forman parte del núcleo esencial de la función representativa parlamentaria ${ }^{17}$ ¿Y cuáles son? El TC ha sido poco preciso. Se ha limitado a decir que «son principalmente los que tienen relación directa con el ejercicio de las facultades legislativas y de control de la acción de Gobierno» [por todas, STC 159/2019, FJ 5 c)], lo que no es decir gran $\operatorname{cosa}^{18}$.

\section{Dos observaciones adicionales}

a) Sobre la necesidad de potenciar el control en el Parlamento

Es obvio que, desde hace ya algún tiempo, el Parlamento como órgano no es, normalmente, un contrapoder al Gobierno. Mayoría parlamentaria y Gobierno van normalmente de la mano y, en consecuencia, el control por el Parlamento, el que ejerce la mayoría, ha perdido buena parte de su eficacia ${ }^{19}$.

Hoy el Parlamento no vive normalmente en contraposición al Gobierno. Hoy la contraposición es entre Gobierno-mayoría parlamentaria y oposición-minoría parlamentaria. Es esta última la verdaderamente interesada en controlar al Gobierno y es a quien hay que dar armas eficaces para llevar esa labor. El Parlamento es — debe ser- «la casa de las minorías», el «hábitat natural» de la oposición ${ }^{20}$.

Si queremos que haya control parlamentario eficaz, hay que situar en primer plano el control en el Parlamento: hay que potenciarlo y garantizarlo jurídicamente.

16 STC 161/1988, FJ 7.

17 STC 220/1991, FJ 5 .

18 Una relación actualizada de los «derechos» que ha reconocido el TC como parte del contenido protegido por el art. 23.2 CE en CidonCha MARTín, A., «La defensa jurídica del estatus parlamentario en el ejercicio de la función de control del Gobierno», ob. cit.

19 Pero no por ello debe dejar de existir, no solo porque la mayoría no siempre forma un bloque con el Gobierno, sino porque «el régimen parlamentario no podría funcionar si se hace desaparecer la diferenciación entre Parlamento y Gobierno, así como la configuración jurídica de ambos como órganos distintos (aunque, por supuesto, relacionados)» [ARAGón ReYEs, M., Constitución y control del poder, ob. cit., p. 173]

20 Las expresiones entrecomilladas las tomo de García RoCA, J., "Control parlamentario y convergencia entre presidencialismo y parlamentarismo», $T R C$ n. ${ }^{\circ} 38,2016$, pp. 71 y 69, respectivamente. 
Sucede que la $\mathrm{CE}$ ha diseñado los instrumentos de control que prevé expresamente como instrumentos de control por el Parlamento. Sucede también que los reglamentos parlamentarios, si bien no ignoran la nueva realidad, son muy cicateros a la hora de conferir «derechos» de control en el Parlamento a las minorías.

Si tomamos como ejemplo el Reglamento del Congreso de los Diputados (RCD en adelante), control en el Parlamento solo hay, en puridad, en las preguntas e interpelaciones y en el acceso a la documentación; en estos tres casos la mayoría no puede frenar el ejercicio del derecho. En todos los demás casos el control parlamentario es, en puridad, control por el Parlamento, en manos de la mayoría. Así ocurre en instrumentos específicos de control parlamentario, como las Comisiones de Investigación o las comparecencias de miembros del Gobierno: los diputados, individualmente o agrupados, pueden pedir que se constituya una Comisión de Investigación o que comparezca tal o cual miembro del Gobierno, pero la creación de la Comisión de Investigación o la comparecencia del miembro del Gobierno está en manos de la mayoría que, obviamente, no tiene demasiado interés en poner en aprietos al Gobierno ${ }^{21}$. Así ocurre también con todos los «derechos» que, sin ser específicamente de control, sirven a la función de control: aquí hay derecho a proponer (v.gr., proposiciones de ley o enmiendas en el procedimiento legislativo) y, por ende, derecho a que se admita a trámite la propuesta para su defensa, si es reglamentaria, pero no derecho a que se acepte finalmente la propuesta.

La doctrina clama desde hace tiempo por mejorar o ampliar los instrumentos de control en el Parlamento, por incorporar otros ${ }^{22}$ e, incluso, por construir un auténtico estatuto de la oposición ${ }^{23}$. No puedo entrar en ello, pero, desde luego, algo hay que hacer, ante ese descorazonador panorama, especialmente en el terreno de la información: si la oposición no tiene acceso razonable a la información del Gobierno, es imposible el enjuiciamiento de la labor de éste. Y, desgraciadamente, la información es frecuentemente escamoteada por el Gobierno, siendo así que esa conducta no merece censura jurídica por el TC. Para el Alto Tribunal, no cabe amparo ante la negativa del Ejecutivo a dar información al parlamentario o ante la respuesta insuficiente de aquel «so riesgo de pretender una judicialización inaceptable de la vida política» (STC 220/1991, FJ 5). Creo que el TC se equivoca. No creo que obligar jurídicamente al Ejecutivo a proporcionar información suficiente a los representantes de los ciudadanos sea una

21 Vid. art. 52.1 RCD (Comisiones de Investigación) y 202-203 RCD (comparecencias).

22 Véase, por ejemplo, Garrorena Morales, A., «Algunas sugerencias para renovar la función de control», ob. cit., pp. 430 y ss.; Tudela ARANDA, J., «La renovación de la función parlamentaria de control», Teoría y Realidad Constitucional, n. ${ }^{\circ}$ 19, 2007, pp. 80 y ss.; SÁNCHEZ MuÑOZ, O., «El afianzamiento del poder de los gobiernos autonómicos y su especial resistencia al control parlamentario», en Matia Portilla, F.J. (coord.), Pluralidad de ciudadanías, nuevos derechos y participación ciudadana, Madrid: CEPC, 2011, pp. 325 y ss.; o ARANDA ÁlvarEZ, E., «El Reglamento del Congreso de los Diputados. Propuestas para su reforma», REP, n. ${ }^{\circ} 175,2017$, pp. 41 y ss.

23 Salvo equivocación por mi parte, el primero en hablar entre nosotros de un estatuto constitucional de la oposición fue Garrorena (Garrorena Morales, A., «Algunas sugerencias para renovar la función de control», ob. cit., p. 430). 
«judicialización inaceptable de la vida política». Más bien, creo que es una judicialización necesaria para que aquellos puedan ejercer la función de control político al Gobierno, la más relevante del Parlamento de nuestro tiempo ${ }^{24}$.

\section{b) Sobre el control parlamentario en tiempos de fragmentación parlamentaria}

La concepción amplia del control parlamentario, que pone el énfasis en el control en el Parlamento, fue postulada en los años ochenta y noventa del siglo pasado, en tiempos de mayorías absolutas o casi absolutas, en los que el control por el Parlamento era poco eficaz. Desde diciembre de 2015 el panorama ha cambiado. Vivimos tiempos (no sé si duraderos) de fragmentación parlamentaria y de gobiernos en minoría y ello ha tenido (está teniendo) consecuencias en la relación entre el Gobierno y el Parlamento ${ }^{25}$.

Tampoco puedo detenerme en este asunto. Solo apunto algunas cosas. En primer lugar, era de prever una cierta revitalización del control por el Parlamento, dada la precaria posición de los Gobiernos. Así ha sido. Hemos asistido a un ejercicio fuerte de control por el Parlamento: la aprobación de una moción de censura (en junio de 2018). Pero también a controles menos intensos, que antes eran rara avis: proposiciones de ley y no de ley que se aprueban, comisiones de investigación que se crean en contra del criterio del Gobierno o mociones de reprobación de ministros que salen adelante (aunque, como sabemos, sin efectos jurídicos vinculantes). Y, en segundo lugar, era también de prever un retraimiento de los Gobiernos, máxime cuando han estado mucho tiempo en funciones. Este retraimiento ha sido un hecho: los Gobiernos en época de fragmentación parlamentaria apenas han podido dirigir la política, mediante la presentación y aprobación de proyectos de ley ante las Cámaras o la presentación y aprobación de presupues$\operatorname{tos}^{26}$, y ello por estar en minoría o, sencillamente, por estar en funciones. Sucede también que los Gobiernos en minoría han utilizado todos los resortes a su alcance para impedir el «gobierno» de la mayoría: desde el veto presupuestario a las proposiciones de ley hasta el uso generoso del decreto-ley, pasando por la negativa a ser controlado, por estar en funciones ${ }^{27}$.

24 Más extensamente sobre esta cuestión, vid. Cidoncha MARTín, A., «La defensa jurídica del estatus parlamentario en el ejercicio de la función de control del Gobierno», ob. cit.

25 Estos efectos han sido muy bien explicados por Piedad García-Escudero (García-Escudero MárQUEZ, P., «Parlamento y Gobierno en tiempos de multipartidismo», Corts, Anuario de Derecho Parlamentario, n. ${ }^{\circ} 33$, 2020, pp. 183-209) y Esperanza Gómez Corona (Goméz CoronA, E., «La desparlamentarización del sistema político español. De parlamentarismo excesivamente racionalizado a un parlamentarismo diluido», $R D P$ n. ${ }^{\circ} 11,2021$, pp. 109-136).

26 Desde diciembre de 2015 hasta diciembre de 2020, solo dos presupuestos aprobados (además, tardíamente), el último de los cuales (el de 2018), por fin dio paso a unos nuevos presupuestos, para 2021.

27 El abuso del veto presupuestario a las proposiciones de ley ha sido frenado por el TC (SSTC $34 \mathrm{y}$ $44 / 2018$ ) y la peregrina idea que un Gobierno en funciones no puede ser controlado por el Parlamento se ha topado también con nuestro Alto Tribunal (STC 124/2018). 
Nuestra forma de gobierno parlamentaria está siendo sometida desde diciembre de 2015 a un estrés muy fuerte y convendría reflexionar sobre ello. No es conforme con nuestra forma de gobierno que el Gobierno huya del Parlamento, pero tampoco lo es que el Parlamento pretende gobernar en su lugar. Forma de gobierno parlamentaria no es igual a gobierno parlamentario o de Asamblea. La mayoría parlamentaria no puede convertir al Gobierno, de sujeto responsable ante el Parlamento, en mero ejecutor de sus instrucciones. El espíritu de la CE es claro: el Gobierno gobierna (dirige la política) y el Parlamento lo controla. El uno debe poder gobernar y el otro debe poder controlar. Así de simple. Si la mayoría no está conforme con el Gobierno, lo procedente es cambiarlo, no imponerle un programa distinto del suyo. Y si el Gobierno tiene dificultades para gobernar, el Presidente tiene a mano tanto la cuestión de confianza como la disolución de las Cámaras. Son las reglas políticas inherentes a nuestra democracia parlamentaria ${ }^{28}$.

\section{SOBRE EL CONTROL PARLAMENTARIO EN NUESTRO DERECHO DE EXCEPCIÓN}

En los «estados de emergencia» previstos en el art. 116 CE para hacer frente a «situaciones de anormalidad constitucional $»^{29}$ no se interrumpe (porque no se puede) el funcionamiento de los poderes constitucionales del Estado (art. 116.5 $\mathrm{CE})$. Por tanto, las Cortes Generales siguen funcionando y deben poder ejercer el control del Gobierno, a través de los instrumentos previstos en la CE y en los reglamentos parlamentarios. Ahora bien, dado el poder extraordinario que se otorga el Ejecutivo, la CE dota de poderes extraordinarios de control (aunque son algo más que eso) a una de las Cámaras, el Congreso de los Diputados. El control extraordinario del Congreso es la contrapartida al poder extraordinario del Gobierno.

Analizaré sintéticamente la regulación de ese control «congresual» extraordinario (por y en) sobre el Gobierno, pero antes, es obligado (al menos, me veo obligado) a hacer unas consideraciones generales sumarias.

\section{Consideraciones generales sumarias}

Nuestra Constitución está entre las Constituciones que, siguiendo al clásico, se adscriben el modelo de «estado de excepción» ${ }^{30}$ y, como tal, contiene una

28 Sobre que la democracia parlamentaria tiene unas reglas políticas, además, de las jurídicas, vid. Aragón Reyes, M., «Legislatura fallida e investidura convulsa. Análisis y consecuencias», REDC, n. ${ }^{\circ} 109$, pp. 15-34.

29 Uso los términos del TC (STC 83/2016, FJ 7, párr. segundo).

30 El clásico es Cruz Villalón. Sigo la distinción que hace entre Constituciones que carecen de Derecho de Excepción y Constituciones que lo tienen; y dentro de estas, entre Constituciones que adoptan el modelo 
regulación extensa de los estados de emergencia constitucional (art. 116, pero también arts. 55, 117.6 y 169). No obstante, se trata de una regulación necesitada de ser completada, a lo que provee la ley orgánica a la que se remite en el art. 116.1: la Ley Orgánica 4/1981, de 1 de junio, de los estados de alarma, excepción y sitio (en adelante LOAES).

$\mathrm{El}$ artículo $116 \mathrm{CE}$ forma parte del título $\mathrm{V}$, aquel que precisamente regula las relaciones entre el Gobierno y las Cortes Generales. El primer apartado menciona los tres estados de emergencia y, como ya he indicado, remite a ley orgánica su regulación. A partir de ahí, el resto de los apartados va dirigido a garantizar un cierto equilibrio entre el Ejecutivo, al que se confieren los poderes extraordinarios, y el Legislativo o, para ser más exactos, a una de las ramas de este, el Congreso de los Diputados. Los apartados 2 a 4 identifican los órganos competentes para su declaración y, en su caso, prórroga y el procedimiento de adopción de tales decisiones, entre otras cosas. En ellos aparece siempre el Congreso, en una relación con el Gobierno directamente proporcional a la gravedad del estado que se declara: cuanto más grave, más intervención del Congreso de los Diputados. En fin, los apartados 5 y 6 contienen «una serie de garantías comunes a los tres estados de emergencia para proteger al ordenamiento constitucional de las consecuencias que se pudieran derivar de la declaración de cualquier de ellos $»^{31}$. En ellos late la preocupación por preservar el equilibrio entre los poderes constitucionales del Estado en general y la posición del Congreso de los Diputados en particular.

La CE no define los tres estados de emergencia constitucional que menciona. Esto es algo que ha hecho la ley a la que se remite. La LOAES se ha ocupado de la definición de cada uno esos estados, en los arts. 4, 13 y 32, respectivamente. Sostenía Cruz Villalón ${ }^{32}$ que la ley no optó por una lectura o concepción posible, la gradualista, conforme a la cual los distintos estados serían expresión de distintos tipos de respuesta a un mismo tipo de emergencia (seguridad del estado) en función de la gravedad de la misma. Optó por una lectura o concepción pluralista, conforme a la cual se trata de estados cualitativamente distintos, previstos para situaciones de emergencia cualitativamente diferentes: el estado de alarma (despolitizado en su paso por el Parlamento $)^{33}$, para emergencias naturales o tecnológicas; el estado de excepción, para alteraciones graves del orden público; el estado

de dictadura constitucional y a aquellas que adoptan el modelo de estado excepcional (Cruz Villalón, P., Estados excepcionales y suspensión de garantías, Madrid: Tecnos, 1984, pp. 31-35). Le sigo, aunque no del todo: para mí, el «tertium genus» entre la dictadura constitucional y el estado excepcional, esto es, Alemania, puede adscribirse sin gran problema al modelo de estado excepcional.

31 STC 83/2016, FJ 7, párr. 4.

32 En 1981, nada más aprobarse la LOAES [CRuZ Villalón, P., «El nuevo Derecho de excepción (Ley Orgánica 4/1981, de 1 de junio)», REDC, n. ${ }^{\circ}$ 2, 1981, pp. 95-96); y en 1984 [CruZ Villalón, P., Estados excepcionales y suspensión de garantías, ob. cit., pp. 51-521.

33 Sobre la evolución del estado de alarma desde el (nonato) proyecto de ley de seguridad ciudadana hasta la aprobación de la LOAES, vid. CruZ Villalón, P., «El nuevo Derecho de excepción (Ley Orgánica 4/1981, de 1 de junio)», ob. cit., pp. 96-99. 
de sitio, para situaciones extremas en las que está en juego la supervivencia del Estado y su ordenamiento constitucional. Esta tesis causó fortuna y se ha convertido en un lugar común entre nosotros ${ }^{34}$.

La CE tampoco precisa los efectos de la declaración de los tres estados de emergencia constitucional. Sin embargo, sí establece una regla fundamental en garantía de los derechos fundamentales: no cabe suspender derecho fundamental alguno en estado de alarma y solo es posible (que no obligatorio) suspender algunos de ellos (no todos) en los estados de excepción y sitio (art. 55.1 CE). En materia de derechos fundamentales, el legislador constituyente traza una nítida barrera entre el estado de alarma y los estados de excepción y sitio. En concreción del art. 116.1, en conexión con el art. 55.1 CE, la LOAES fija los términos de suspensión de los derechos susceptibles de ser suspendidos (arts. 16 a 23 y 33) y, de paso, habilita al Gobierno para adoptar determinadas medidas susceptibles de limitar (que no suspender) derechos fundamentales (arts. 11 y 12).

\section{El control parlamentario extraordinario en nuestro Derecho de excepción}

Las situaciones de emergencia constitucional son gestionadas por el Ejecutivo, un poder más preparado que el Legislativo para afrontarlas. Como contrapartida, las Constituciones con modelo de «estado excepcional» procuran limitar daños, los que inevitablemente se derivan de la concentración de poderes de emergencia en el Ejecutivo. A tal efecto, intentan garantizar que esa concentración impacte lo menos posible en los dos pilares sobre los que se asienta toda Constitución: la división de poderes y los derechos fundamentales.

\section{a) Las garantías comunes a los tres estados de emergencia constitucional}

La CE procura esa doble garantía. Interesa aquí la garantía de la división de poderes. A este respecto, el apartado 5 del art. 116 es taxativo: el funcionamiento de las Cámaras y de los demás poderes constitucionales del Estado no podrá interrumpirse durante la vigencia de ninguno de los tres estados de emergencia constitucional. «The show must go on», parece decirnos el legislador constituyente.

34 Matizo: esos estados no son compartimentos estancos, tienen puntos de conexión, especialmente entre el estado de alarma y el de excepción. Por eso el art. 28 LOAES dispone que, cuando una grave alteración del orden público haya dado lugar $a$ o coincida con uno de los supuestos del estado de alarma, el Gobierno podrá adoptar las medidas previstas para el estado de alarma, además de las previstas para el de excepción. Ello es lógico: los supuestos de hecho del estado de alarma son causas (art. 4 LOAES), los supuestos de hecho del estado de excepción son efectos (art. 13 LOAES). Una crisis sanitaria, tal como una epidemia (supuesto del estado de alarma), puede producir como efecto una grave alteración del orden público, en concreto, una grave alteración de un servicio público esencial (el sanitario), supuesto del estado de excepción. Véase, en esta línea, la STC 148/2021, de 14 de julio, FJ 11. En definitiva, las fronteras entre los diversos estados no están precisamente cerradas. 
Más taxativa es aún la LOAES: la declaración de cualquiera de los estados de emergencia «no interrumpe el normal funcionamiento de los poderes constitucionales del Estado» (art. 1.4 LOAES — la cursiva es mía). «La vida sigue igual», parece decirnos el legislador orgánico.

No estuvo afortunado el legislador orgánico con el adjetivo «normal». La vida no sigue igual. La declaración de los estados de emergencia constitucional, incluido el menos intenso, el estado de alarma, altera el funcionamiento de los poderes constitucionales del Estado. Para empezar, engorda al Gobierno, al que se le otorgan poderes extraordinarios que, en circunstancias de normalidad, no podrían ejercer. Este engrosamiento del Gobierno afecta a la división vertical del poder: las medidas gubernamentales pueden legítimamente afectar al ejercicio (que no a la titularidad) de las competencias de las comunidades autónomas. Estas pueden seguir ejerciendo sus competencias, pero sus normas y actos pueden verse desplazadas cuando sean contrarias a las medidas adoptadas por el Gobierno.

El engrosamiento del Gobierno afecta también a la división horizontal de poderes, en concreto, a las relaciones con las Cortes Generales. Téngase en cuenta que, por mor de la declaración de cualquiera de esos estados, que tiene rango de ley, se pone en manos del Gobierno una legalidad excepcional, que desplaza la legalidad ordinaria, la establecida por las Cortes Generales ${ }^{35}$. Esto no es normal $y$, puesto que no es normal, la CE busca preservar la posición del Legislativo, el órgano encargado de supervisar los poderes exorbitantes que se atribuyen temporalmente el Gobierno.

En primer lugar, la CE busca asegurar la permanencia del Legislativo: «No podrá procederse a la disolución del Congreso mientras estén declarados algunos de los estados comprendidos en el presente artículo» (art. 116.5 CE ${ }^{36}$ ). Tampoco cabe disolver el Senado, pues durante la vigencia de los estados de emergencia constitucional no puede interrumpirse el funcionamiento de las Cámaras ni de los demás poderes constitucionales del Estado (ibidem). Queda vedado pues, al Presidente del Gobierno, proponer al Rey la disolución de las Cámaras ex art. 115 CE. Tampoco puede procederse a su disolución automática ex art. 99.5 CE. Entiéndase bien: lo vedado es la disolución en sentido estricto, esto es la expiración anticipada del mandato parlamentario. Si transcurren cuatro años desde las elecciones, expira el mandato de las Cortes Generales y sus funciones pasan a ser ejercida por la Diputación Permanente, incluidas las extraordinarias del Congreso en relación con los estados de emergencia (art. 116.5 in fine $)^{37}$.

35 STC 83/2016, FF.JJ. 9 y 10.

36 El precepto también dispone que las Cámaras sean automáticamente convocadas si no están en período de sesiones. Dice acertadamente Cruz Villalón que esta cautela resulta en cierta medida superflua, «dado que el Congreso ya ha tenido que ser convocado para autorizar o declarar el estado excepcional (con la excepción del estado de alarma inferior a quince días). La garantía opera, pes, prácticamente, en relación con el Senado» (Cruz Villalón, P, Estados excepcionales y suspensión de garantías, ob. cit., p. 135)

37 En el mismo sentido, Cruz Villalón, P, Estados excepcionales y suspensión de garantías, ob. cit., p. 134. 
En segundo lugar, la CE busca asegurar que el engrosamiento del Gobierno no genere impunidad, ni política ni jurídica: «La declaración de los estados de alarma, de excepción y sitio no modificarán el principio de responsabilidad del Gobierno y de sus agentes reconocido en la Constitución y en las leyes» (art. 116.6). La responsabilidad a la que se refiere el precepto no solo es la jurídica sino la política, reconocida expresamente en la CE (art. 108). El art. 116.6 CE no distingue entre la una y la otra y ubi lex non distinguit nec nos distinguere debemus. Es posible presentar una moción de censura durante la vigencia de los estados de emergencia constitucional $^{38}$. Si prospera, no se interrumpe el funcionamiento del Gobierno. Al Gobierno cesado le sustituye casi de inmediato otro. Es la consecuencia del carácter constructivo de nuestra moción de censura.

b) Las garantías específicas: del estado de emergencia «gubernamental» a los estados de emergencia «congresuales»

La CE establece una distinción nítida entre los estados de emergencia en relación con los derechos fundamentales: de un lado, el estado de alarma, en el que no pueden suspenderse aquellos, de otro, los estados de excepción y sitio, en los que sí pueden suspenderse algunos. En relación con la intervención del Congreso también establece una distinción, pero no coincide exactamente con la que acabo de mencionar. La distinción es aquí entre la declaración del estado de alarma, por un lado, y la prórroga del estado de alarma, la declaración y prórroga del estado de excepción y la declaración del estado de sitio, por otro.

i) La declaración del estado de alarma: un estado de emergencia «gubernamental»

La declaración del estado de alarma es una competencia exclusiva del Gobierno, que no está sujeta a control parlamentario previo. Se articula mediante decreto (con rango de ley) acordado en Consejo de Ministros, en el que debe determinarse el ámbito territorial, la duración, que no podrá exceder de quince días, y los efectos de la declaración (arts. 116.2 CE y 6 LOAES). La CE otorga todo el poder al Gobierno. El estado de alarma es, en principio, un estado de emergencia estrictamente gubernamental.

El control extraordinario del Congreso es a posteriori y poco intenso. El art. 116.2 CE se limita a señalar que el Gobierno debe dar cuenta del decreto al Congreso, reunido inmediatamente al efecto. El art. 8 LOAES añade que el Gobierno debe suministrar al Congreso la información que le sea requerida y que, además, debe darle cuenta de los decretos que dicte durante la vigencia del estado de alarma que tengan que ver con dicho estado. En fin, el art. 162.1 RCD dispone que esa información deberá remitirse a la Comisión competente, que podrá recabar la información y documentación que estime pertinente. 
En palabras del TC, este control es una mera «dación de cuentas» del Gobierno al Congreso o, en otras palabras «un mecanismo de información» que puede activar, en su caso, un control político sobre la declaración del estado de alarma y las medidas adoptadas al respecto, bien que este eventual control político «no condiciona ni altera» el contenido del decreto por el que se ha llevado a cabo la declaración del estado de alarma (STC 83/2016, FJ 8).

Añado algo: el control está en manos de la Comisión competente (la Comisión Constitucional del Congreso), no de los parlamentarios o de los grupos parlamentarios. Es un control por el Congreso y, por ello, potencialmente poco eficaz, porque está en manos de la mayoría. Será esta la que decidirá la información y documentación que le deba requerir el Gobierno. Lógicamente, los parlamentarios podrán hacer uso del art. $7 \mathrm{RCD}$, pero ya sabemos en que se traduce este derecho, según el TC: existe derecho a solicitar información y documentación al Gobierno y a que esta se tramite, pero no la obligación jurídica del Gobierno de contestar o de contestar de forma suficiente, so pretexto de una judicialización inaceptable de la vida política ${ }^{39}$.

El art. 116.2 CE dispone que, una vez declarado el estado de alarma, el Congreso debe reunirse inmediatamente al efecto de recibir la dación de cuentas del Congreso. La duda es si, para cumplir esta exigencia constitucional, basta con la comunicación a la Comisión competente ex art 162.1 RCD, o si también ha de someterse al Pleno, tal como exige el art. $165 \mathrm{RCD}$ «en los supuestos previstos en los tres artículos anteriores», que se ocupan de la tramitación parlamentaria de cada uno de los estados de emergencia constitucional, entre ellos la declaración del estado de alarma (art. 162.1 RCD). La respuesta que parece haber dado el TC es que la reunión del Pleno de la Cámara es una posibilidad, no una obligación (STC 83/2016, FJ 8, p. 2 in fine).

ii) Los estados de emergencia «congresuales»: estado de alarma prorrogado, estado de excepción y estado de sitio

Es muy gráfico el TC: la intervención del Congreso es, para empezar, previa a la declaración de la prórroga. Además, no solo es «un presupuesto para decretar la prórroga del estado de alarma». Es mucho más, es «un elemento determinante del alcance, de las condiciones y de los términos» de la prórroga, sean estos «bien establecidos directamente por la propia Cámara, bien por expresa aceptación de los propuestos en la solicitud de prórroga, a los que necesariamente ha de estar el

39 STC 220/1990, FJ 5, ya citada. Algo se mueve, no obstante, no en el TC, sí en el Tribunal Supremo. En dos sentencias de la sección 7 de la Sala de lo Contencioso-Administrativo (de 25-2-2013 y de 1-6-2015) admite que, frente la negativa del Gobierno a responder a una solicitud de información parlamentaria es posible recurrir a la justicia ordinaria, en vía preferente y sumaria, por violación del art 23.2 CE. Una respuesta no fundada en derecho del Gobierno puede suponer una lesión del art. 23.2 CE. Sobre esta cuestión, CidonCHA MARTín, A., «La defensa jurídica del estatus parlamentario en el ejercicio de la función de control del Gobierno», ob. cit. 
decreto que la declara» (STC 83/2016, FJ 8 p. 3). Siendo esto así, el decreto gubernamental de prórroga «se limita a formalizar y exteriorizar el acto parlamentario de autorización» (STC 83/2016, FJ 10 in fine).

A efectos de intervención del Congreso, la prórroga del estado de alarma se equipara a la autorización (y prórroga) del estado de excepción ex art. 116.3 CE. La decisión material corresponde al Congreso y su formalización al Gobierno. Más allá se va en el estado de sitio: la decisión, material y formalmente, compete al Congreso de los Diputados (art. 116.4 CE). En cuanto a su declaración, el estado de alarma prorrogado y el estado de excepción (y su prórroga) son estados materialmente «congresuales»; y el estado de sitio es un estado «congresual», formal y materialmente.

Se comprende así que los trámites previstos en el RCD (arts. 162 a 165) sean los mismos. La primera fase es la solicitud por el Gobierno de la prórroga del estado de alarma, del estado de excepción o su prórroga o la propuesta del Gobierno del estado de sitio. Una vez recibida la solicitud o propuesta y admitida a trámite por la Mesa del Congreso, la segunda fase es la parlamentaria: el asunto es sometido al Pleno de Congreso, convocado al efecto si no estuviera reunido. En caso de estar disuelto, las competencias del Pleno pasan a la Diputación Permanente del Congreso. La convocatoria es obligatoria, no está en manos del Presidente del Congreso o de la mayoría.

En esta segunda fase hay una primera subfase, de control en el Congreso: los grupos parlamentarios podrán presentar propuestas sobre el alcance y las condiciones de la prórroga del estado de alarma, el estado de excepción y el estado de sitio hasta dos horas antes de la sesión en que hayan de debatirse (art. 162.3 RCD, al que se remiten los arts. 163 y $164 \mathrm{RCD}$ ). Se trata de una suerte de facultad de enmienda de la propuesta gubernamental, pero no de veto de la misma. Si los grupos parlamentarios no desean acordar la autorización, el momento procesal oportuno para pronunciarse es la votación final. Por lo demás, está facultad encaja sin dificultad en el contenido del derecho fundamental al ejercicio del cargo público representativo ex art. $23.2 \mathrm{CE}^{40}$. Los grupos parlamentarios pueden defenderla, en su caso, en amparo ante el TC. Entiéndase bien: lo garantizado es el ius ut procedatur: el derecho a que se admitan a trámite las propuestas, si reúnen los requisitos reglamentarios y a que se debatan, no a que se aprueben, lógicamente ${ }^{41}$.

La segunda subfase es la de debate y votación en el Pleno del Congreso (art. 162.4 RCD, al que se remiten los arts. 163 y 164). El debate se inicia con

40 El TC ha incluido dentro del derecho fundamental ex art. 23.2 CE el derecho a presentar enmiendas en el procedimiento legislativo (v.gr., SSTC 23/1990, 118/1995, 27/2000, 139/2017 o 4/2018). Estamos ante un supuesto similar.

41 Sobre las facultades de calificación de las Mesas, vid. Cidoncha Martín, A., «La defensa jurídica del estatus parlamentario en el ejercicio de la función de control al Gobierno», ob. cit. Creo que, por analogía con lo declarado últimamente por el TC en relación con la facultad de enmienda (STC 119/2021), sería contrario al art. 23.2 CE la admisión por la Mesa de enmiendas que no guarden relación con la propuesta del Gobierno. 
una exposición del Gobierno de las razones que justifican su solicitud o propuesta y se ajusta a las normas previstas para los debates de totalidad. Esto significa que los grupos parlamentarios tienen ocasión de fijar posición durante diez minutos como máximo (art. 74.2 RCD). Se garantiza así, aunque más bien poco, su derecho a intervenir en un debate extraordinariamente relevante en el que, entre otras cosas, se puede estar decidiendo la suerte de los derechos fundamentales de los ciudadanos. Finalizado el debate, se votan las propuestas presentadas y, posteriormente, la solicitud o propuesta del Gobierno con las propuestas de los grupos parlamentarios que hubieran sido aceptadas por la Cámara ${ }^{42}$.

En definitiva: en los estados de emergencia «congresuales», el Gobierno propone y el Congreso dispone. El Gobierno tiene el monopolio de la iniciativa, el Congreso el de la decisión y de su contenido. Hay un intenso control por el Congreso, poco eficaz cuando la mayoría del Congreso y el Gobierno coinciden (lo normal), pero muy relevante si un Gobierno está en minoría. Por último, también hay control en el Congreso: la facultad de los grupos parlamentarios de hacer propuestas y el tiempo de intervención en el debate.

¿Puede revocar el Congreso antes del fin del plazo la autorización conferida al Gobierno para prorrogar el estado de alarma o para decretar el estado de excepción o su prórroga? Ante el silencio de la CE y del legislador, entiendo que, una vez emitido el decreto correspondiente por el Gobierno, no cabe la revocación: la autorización se agota con el uso de la misma por el Gobierno emitiendo el oportuno decreto. Es este el que puede poner fin al estado de excepción antes de que finalice dicho plazo, dando cuenta al Congreso de los Diputados, si ha conseguido restablecer la situación de normalidad. Así lo dispone el art. 15.2 LOAES para el estado de excepción y, entiendo que esta solución es predicable, por analogía, también para la prórroga del estado de alarma. Al fin y al cabo, la vigencia de los estados de emergencia constitucional está sujeta a un límite circunstancial: que circunstancias extraordinarias hagan imposible el mantenimiento de la normalidad mediante los poderes ordinarios de las autoridades competentes (art. 1.1 LOAES). Si se restablece la normalidad antes de tiempo, no procede continuar con el Derecho de excepción. Lo que no puede hacer el Gobierno es modificar su decreto sin contar con la autorización del Congreso. Así lo dispone el art. 15.1 LOAES para el estado de excepción, predicable también para la prórroga del estado de alarma y del estado de excepción.

¿Puede revocar el Congreso antes del fin del plazo la declaración del estado de sitio o modificarla? Entiendo que sí: la declaración es suya. Sucede que habrá de hacerlo mediante una nueva declaración y esta solo será posible a partir de una

42 Solo es necesaria la mayoría simple para la autorización de la prórroga del estado de alarma y para la autorización del estado de excepción o su prórroga. En necesaria la mayoría absoluta para la declaración del estado de sitio (art. 116.4 CE). Entiendo que la mayoría absoluta se exige para la votación final del conjunto del texto, con las propuestas que hayan sido admitidas (por mayoría simple). 
propuesta del Gobierno, que tiene el monopolio de la iniciativa. La revocación o modificación solo será posible si el Gobierno quiere.

\section{SOBRE EL CONTROL PARLAMENTARIO Y LAS ALARMAS DECRETADAS EN TODO EL TERRITORIO NACIONAL PARA CONTENER LA PANDEMIA}

\section{Sobre la primera alarma decretada en todo el territorio nacional para contener la pandemia}

La primera alarma en todo el territorio nacional desencadenada por la pandemia [art. 4 b) LOAES)] fue decretada por el Gobierno el 14 de marzo de 2020 (Real Decreto 463/2020, de 14 de marzo, modificado por Real Decreto 465/2020, de 17 de marzo) y se extendió hasta el 21 de junio de ese año, merced a seis prórrogas autorizadas por el Congreso y formalizadas después mediante los oportunos decretos gubernamentales. Más de tres meses estuvimos bajo una alarma extraordinariamente dura, por las medidas que en él se adoptaron, más propias de un estado de excepción ${ }^{43}$. Esto lo podemos decir ahora: la STC 148/2021, de 14 de julio (recién salida del horno al tiempo de entregarse este trabajo) ha declarado que el confinamiento general de la población acordado en el estado de alarma (art. 7 del Real Decreto 463/2020) implicó una suspensión de la libertad de circulación y residencia ex art. $19 \mathrm{CE}^{44}$. No voy a entrar en ello: excede del objeto de mi trabajo.

\section{a) El control «congresual» extraordinario del estado de alarma}

Entra en el objeto de mi trabajo evaluar si se ejerció correctamente el control extraordinario que la CE (completada por la LOAES y el RCD) asigna al Congreso en contrapartida a los poderes extraordinarios atribuidos al Gobierno. La respuesta es afirmativa: se respetaron las garantías específicamente previstas para el estado de alarma.

En lo que hace al estado de alarma «gubernamental», el Gobierno dio cuenta al Congreso de la declaración de estado de alarma, enviando la oportuna comunicación (el 15 de marzo de 2020), que fue trasladada por la Mesa del Congreso a la Comisión Constitucional del Congreso (el 17 de marzo de 2020) ex art 162.1 RCD. Desde ese momento la citada Comisión podía recabar la información y

$43 \mathrm{Al}$ menos hasta mayo, en que se inició la desescalada, tras la aprobación por el Gobierno del Plan de Transición hacia la nueva normalidad (el 28 de abril de 2020). Con la desescalada se fueron relajando progresiva y asimétricamente las medidas inicialmente adoptadas.

44 Los razonamientos específicos, en el FJ 5. 
documentación que estimase pertinente (art. 8.1 LOAES y 162.1 RCD). Es más, lo que el TC ve como posibilidad (y no como obligación), se hizo realidad: el Presidente del Gobierno compareció ante el Pleno del Congreso de los Diputados (el 18 de marzo de 2020) para cumplimentar lo previsto en el art. 165 RCD.

En lo que hace a los estados de alarma «congresuales», los derivados de las seis prórrogas, el Gobierno sometió al Congreso las sucesivas propuestas de prórroga, que fueron autorizadas por éste, tras cumplimentarse los trámites del art. 162 RCD. Las prórrogas fueron todas por 15 días. Debe destacarse también que el Congreso admitió algunas propuestas de los grupos parlamentarios, entre ellas, una del PNV (en la primera prórroga), que se tradujo en una nueva Disposición Adicional 6. ${ }^{a}$ del decreto de alarma. En ella se disponía, de acuerdo con el art. 8.1 LOAES, que «el Gobierno remitirá semanalmente al Congreso de los Diputados información documental estructurada de la ejecución de las distintas medidas adoptadas y valoración de su eficacia para contener el virus COVID-19 y mitigar su impacto sanitario, económico y social».

Esta remisión de información y de valoración era, a mi juicio, una obligación jurídicamente vinculante para el Gobierno, establecida en una norma con rango de ley. No dependía pues, de su voluntad o de la voluntad de la mayoría en el Congreso. Venía a reforzar no solo el control por, sino también el control en el Congreso: a la minoría no se le podía hurtar esa información y esa valoración. Bien mirado, también venía, de alguna manera, a intentar tapar la fuga del control «congresual» que auspiciaba el decreto de alarma, cuando habilitaba a los ministros designados como «autoridades competentes delegadas» para adoptar medidas varias (mediante orden u otros instrumentos) ${ }^{45}$. El artículo 8.2 de la LOAES obliga al Gobierno a dar cuenta al Congreso de los Diputados de los «decretos» que dicte durante la vigencia del estado de alarma «en relación con este». Nada dice de las órdenes (y demás disposiciones) de los ministros erigidos por el decreto de alarma en autoridades delegadas, dictadas en relación con el estado de alarma ${ }^{46}$.

45 Vid. arts. 4.3, 7.6 (introducido en la tercera prórroga), 10.6 (igualmente introducido en la tercera prórroga), 13, 14.1 y 4, 15 y 17 del Real Decreto 463/2020, de 14 de marzo. Sobre los problemas (y dudas) de la delegación en cuatro ministros ex art. 4 del citado Real Decreto, vid. SANTAMARía PASTOR, J.A., «Notas sobre el ejercicio de las potestades normativas en tiempos de pandemia», en VV.AA., Covid-19 y el Derecho Público, Valencia: Tirant lo Blanch, 2020, pp. 205-237.

46 En relación con el art. 10.6 del decreto de alarma (RD 463/2020, de 14 de marzo), introducido (antes de la primera prórroga) por el Real Decreto 465/2020, de 17 de marzo, que lo modificó, el TC ha declarado, en la STC 148/2021, de 14 de julio, lo siguiente: «El apoderamiento al titular de un departamento ministerial para alterar (... «modificar», «ampliar» o «restringir») lo dispuesto por el Consejo de Ministros en el Real Decreto ... permitió, en definitiva, que la libertad de empresa fuera limitada más allá de lo previsto en los apartados 1, 3 y 4 [del artículo 10] del Real Decreto sin la correspondiente dación de cuentas al Congreso de los Diputados; garantía de orden político de la que no cabe en modo alguno prescindir». Según deduzco de este pasaje, sin dación de cuentas al Congreso, las alteraciones del decreto de alarma llevadas a cabo por las autoridades delegadas serían inconstitucionales. 


\section{b) El funcionamiento anormal del Congreso de los Diputados (pero también del Senado $y$ de los Parlamentos autonómicos)}

Ya he dicho que la declaración de los estados de emergencia afecta al funcionamiento normal de los poderes del Estado. La infeliz expresión del art. 1.4 LOAES solo puede interpretarse conforme a la Constitución: la afectación a su funcionamiento (que, en ningún caso puede suponer su interrupción) debe ser únicamente la que deriva necesariamente del estado de emergencia declarado. V.gr., en relación con las Cortes Generales, es normal que dicha declaración genere una legalidad provisional con capacidad para desplazar la legalidad ordinaria, aunque no la CE (salvo lo que ella misma ha permitido desplazar) ni la LOAES.

Sucede que ni el Congreso de los Diputados, ni el Senado, ni las Asambleas Autonómicas funcionaron normalmente durante la vigencia del primer estado de alarma. Ese funcionamiento anormal no fue consecuencia de la declaración del estado de alarma (el Derecho), sino, como gráficamente se ha dicho, de la causa de dicha declaración: la pandemia (el hecho), que «ha obligado a adoptar medidas para limitar el contagio y que afectan a la proximidad entre las personas, los desplazamientos de las mismas, la continuidad de las actividades empresariales y de la prestación de servicios, entre otras» ${ }^{47}$. La dichosa pandemia afectó a la actividad parlamentaria en sí, que fue suspendida durante un tiempo y a su presencialidad.

Centro mi atención en el Congreso de los Diputados ${ }^{48}$. Durante prácticamente un mes la actividad del Congreso estuvo bajo mínimos. El 10 de marzo de 2020, la Presidenta del Congreso acordó con la Mesa y la Junta de Portavoces suspender la actividad parlamentaria durante toda la semana, incluido el pleno. El 12 de marzo de 2020, por acuerdo de la Junta de Portavoces, se suspendió la actividad parlamentaria (plenaria y de comisión) durante 15 días; y el 19 de marzo de 2020, por acuerdo de la Mesa, se suspendieron los plazos reglamentarios y administrativos. Esta suspensión se levantó el 7 de abril de 2020, casi coincidiendo en el tiempo con la autorización de la segunda prórroga del estado de alarma (el 9 de abril de 2020), lo que permitió la paulatina

47 Secretaría General del Senado, «Nota sobre la conformidad a derecho del acuerdo adoptado por la Mesa del Senado en su reunión del día 17 de marzo de 2020, relativo a la limitación de la convocatoria de sesiones del Pleno y de las Comisiones del Senado durante el estado de alarma», Revista de las Cortes Generales, n. ${ }^{\circ} 110,2021$, p. 477.

48 Respecto del Senado y los Parlamentos autonómicos, me remito a Piedad García-Escudero (GARCía-Escudero Márquez, P., «La ductilidad del Derecho Parlamentario en tiempos de crisis: actividad y funcionamiento de los Parlamentos durante el estado de alarma por Covid-19», TRC, n. ${ }^{\circ} 46,2020$, pp. 271308). Respecto de las Cortes Generales únicamente, vid. también García de EnTErría Ramos, A. y NavaRro Mejía, I., «La actuación de las Cortes Generales durante el estado de alarma para la gestión de la crisis del Covid-19», RCG , n. ${ }^{\circ}$ 108, 2020, pp. 245-288; y ORTEA GARCíA, E., Cortes Generales y emergencia sanitaria: labor parlamentaria en un contexto distópico. Una panorámica de la adaptación práctica del Derecho Parlamentario espanol a la crisis de la Covid-19, Zaragoza: Fundación Manuel Giménez Abad de Estudios Parlamentarios y del Estado Autonómico, Colección Estudios, n. ${ }^{\circ}$ 8, 2020. 
reanudación de la actividad parlamentaria, comenzando por las sesiones plenarias de control al Gobierno.

En todo este tiempo, el Congreso no pudo ejercer con normalidad sus funciones, aunque no resultó tan malparado como el Senado o los Parlamentos autonómicos. En razón de sus competencias exclusivas al respecto, pudo ejercer el control «extraordinario» del estado de alarma (ya se ha explicado) y el control de ratificación (convalidación o derogación) de los decretos-leyes aprobados por el Gobierno. También hubo comparecencias del Ministro de Sanidad en la Comisión de Sanidad. Y siempre se pudo preguntar al Gobierno por escrito, aunque se suspendió el plazo de 20 días que este tiene para contestar (art. 192 RCD). Hubo algo de vida parlamentaria en el Congreso, pero la actividad parlamentaria estuvo bajo mínimos en la Cámara baja. El Congreso no cerró, pero estuvo lejos de estar plenamente abierto.

Me pregunto si esta anormalidad es reprochable. Es verdad que «funcionamiento normal de las Cámaras» no es igual a reunión permanente de estas. Significa que sus órganos se reúnen cuando son reglamentariamente convocados. Habrá días en que no hay sesiones parlamentarias, sin que ello implique que las Cámaras hayan dejado de funcionar ${ }^{49}$. Además, la Mesa del Congreso no pueden suspender los períodos ordinarios de sesiones (art. $73 \mathrm{CE}$ ), pero sí reprogramar el calendario de actividades del Pleno y las Comisiones (art. $31.6 \mathrm{RCD})^{50}$. Acaso esta anormalidad no merezca reproche jurídico, a poco que seamos indulgentes ${ }^{51}$. Pero también es verdad que nuestro país forma parte, junto con Letonia y Lituania, del pequeño grupo de países de la UE cuyos Parlamentos suspendieron durante un tiempo sus sesiones. La mayoría de los Parlamentos de la UE decidieron mantener las sesiones parlamentarias, incluso en lo más duro de la crisis, aun reduciendo su número ${ }^{52}$. En retrospectiva, quizá podíamos haberlo hecho mejor y, mirando al futuro, quizá debamos mejorar.

Anormal fue también que se redujera la presencialidad en el Congreso. El 19 de marzo de 2020, la Mesa llegó por unanimidad al siguiente acuerdo: mientras

49 Secretaría General del Senado, «Nota sobre la conformidad a derecho ...», ob. cit., pp. 473-474.

50 Claro está: una cosa es reprogramar la actividad parlamentaria y otra suspenderla por tiempo indeterminado. Esto es, a la postre, lo que el TC ha entendido que hizo el acuerdo de la Mesa del Congreso de 19 de marzo de 2020, que ha declarado inconstitucional. Vid. nota siguiente.

51 En el momento de corregir las pruebas de este trabajo, se ha publicado en la página web del TC el contenido de la sentencia (con fecha de 5 de octubre de 2021) que estima el recurso de amparo presentado por 52 diputados del grupo parlamentario VOX contra el acuerdo de la Mesa del Congreso de 19 de marzo de 2020, arriba citado. El TC no es indulgente: en su parecer, la decisión de la Mesa suspendió por plazo indeterminado la tramitación de las iniciativas parlamentarias de los miembros de la Cámara [FJ 5.A], implicó «en sí misma un desapoderamiento de la función que la Constitución ha conferido al Congreso de los Diputados como es la del control del Ejecutivo»y, «afectó al contenido esencial del ius in officium de los recurrentes» [FJ 5.B.(i)]. La sentencia, que cuenta con tres votos particulares, bien merece un comentario específico. Aquí nos limitamos in extremis a dejar constancia de ella.

52 Díaz Crego, M. y Kostanidis, S. «States of emergency in response to the coronavirus crisis. Normative response and parliamentary oversight in EU Members States during the first wave of the pandemic», European Parlamentary Research Service, 2020, p. 31. 
dure el estado de alarma, y previa petición del grupo parlamentario, todos los diputados que lo deseen podrán emitir su voto por el procedimiento telemático en las sesiones plenarias que se celebren. El acuerdo (nunca publicado) ${ }^{53}$, establecía una excepción no prevista en el art. 82.2 RCD a la presencialidad del voto. Téngase en cuenta que el artículo 79.3 RCD permite que se computen como presentes en la votación los miembros de la Cámara que, pese a estar ausentes, hayan sido autorizados por la Mesa a participar en la misma. Se pudo así sortear el art. 79.1 CE, que exige la asistencia de la mayoría de los miembros de la Cámara para adoptar acuerdos válidamente. Así las cosas, el 25 de marzo de 2021 se celebró sesión plenaria (para la convalidación de 5 decretos-leyes y para autorizar la que fue primera prórroga del estado de alarma) con la presencia de tan solo 43 diputados (una décima parte de los diputados, según acuerdo alcanzado entre los portavoces, así como los miembros de la Mesa) y con la habilitación para todos los diputados del voto telemático (se emitieron 306 votos por esta vía).

En cambio, pese a la petición expresa de algún grupo parlamentario y, después, pese a alguna proposición de reforma del $\mathrm{RCD}^{54}$, no cuajó la posibilidad de deliberar por vía telemática. La Secretaría General del Congreso, en una nota de 25 marzo de 2020, sobre la posibilidad de realizar sesiones del Pleno, las comisiones u otros órganos de la Cámara mediante videoconferencia, se pronunció en contra en lo que respecta a las sesiones del Pleno y las comisiones, salvo que se modifique el Reglamento del Congreso de los Diputados y por motivos excepcionales ${ }^{55}$.

El artículo 79.3 CE dispone que el voto de senadores y diputados es personal e indelegable. Sin embargo, esta regla, como regla absoluta, ha quebrado ${ }^{56}$. Ha quebrado la personalidad del voto: en algunos reglamentos parlamentarios autonómicos está previsto el voto delegado, con base en que el citado artículo solo es predicable en sentido estricto de las Cortes Generales ${ }^{57}$. También ha quebrado la presencialidad del voto: en reglamentos parlamentarios autonómicos, pero también en el RCD (el citado art. 82.2) y en el Reglamento del Senado (art. 92.3) se admite como excepción el voto telemático.

El TC ha avalado la excepción a la regla. En las SSTC 19 y 45/2019 ha venido a decir que las funciones representativas y, por ende, todas las actuaciones

53 Tengo noticia de ella indirectamente [García-Escudero Márquez, P., «La ductilidad del Derecho Parlamentario en tiempos de crisis ...», ob. cit., p. 298]

54 La petición fue de Ciudadanos y la proposición, de Podemos (proposición de reforma, admitida a trámite por la Mesa el 17 de abril de 2020).

55 Tengo noticia de ella indirectamente [García-Escudero Márquez, P., «La ductilidad del Derecho Parlamentario en tiempos de crisis ...», ob. cit., pp. 298-2301. El fundamento de la negativa lo encuentra la Secretaría General en el art. 79.2 RCD y en la jurisprudencia del TC (SSTC 19 y 45/2019).

56 Muy crítico se mostró con las primeras quiebras de la regla Josu de Miguel (De Miguel BárCenas, J., «La personalidad e indelegabilidad del voto y las reformas de los reglamentos de los Parlamentos autonómicos», REDC, n. ${ }^{\circ}$ 90, 2010, pp. 149-169).

57 Vid. Ortea García, E., Cortes Generales y emergencia sanitaria ..., ob. cit., p. 108, tabla 17. Esta interpretación contaba con apoyo en la jurisprudencia del TC (STC 79/1989, FJ 6). 
parlamentarias, han de desarrollarse de forma personal y presencial, como regla general. Sin embargo, esta regla general admite excepción. En lo que hace a la personalidad, la excepción (la delegación) es válida siempre que se justifique en la necesidad de salvaguardar un bien constitucional merecedor de mayor protección. En lo que hace a la no presencialidad, la excepción es válida siempre que venga establecida en los reglamentos parlamentarios y en tanto concurran circunstancias excepcionales o de fuerza mayor ${ }^{58}$.

Es obvio que la pandemia es una circunstancia excepcional o de fuerza mayor que podría justificar el voto telemático. Sin embargo, no está prevista expresamente esta posibilidad en el RCD. Pero no había tiempo para reformar el Reglamento. Acaso habría bastado con una Resolución supletoria de la Presidencia del Congreso, con acuerdo favorable de la Mesa y la Junta de Portavoces (art. 32.2 RCD), a la espera de la reforma del RCD. Creo que introducir la excepción mediante un simple acuerdo de la Mesa, ni siquiera publicado, no fue conforme a derecho, por mucha unanimidad que suscitara. La tradicional flexibilidad del ordenamiento parlamentario tiene su límite en la CE y en el Tribunal que la interpreta ${ }^{59}$.

\section{Sobre la segunda alarma decretada en todo el territorio nacional para contener la pandemia}

a) Consideraciones generales

El 21 de junio de 2020 finalizó el estado de alarma, pero no, desgraciadamente, la crisis sanitaria provocada por la pandemia. La responsabilidad del control de la pandemia se hizo recaer en las comunidades autónomas, que recuperaron el ejercicio pleno de sus competencias sanitarias. Para ello, no tenían más instrumento jurídico que la legislación sanitaria (la básica estatal y la propia), bajo el suave manto básico del Decreto-Ley 21/2020, de 9 de junio (el llamado decreto-ley de nueva normalidad, hoy convertido en Ley - Ley 2/2021, de 29 de marzo) y bajo la mirada atenta del Consejo Interterritorial del Sistema Nacional de Salud (CISNS), presidido por el Ministro de Sanidad y en el que están representadas todas las Comunidades Autónomas. Sobre este órgano recayó la responsabilidad de coordinar la actuación de las comunidades autónomas, mediante la emisión de «declaraciones de actuaciones coordinadas en salud pública» ${ }^{60}$.

58 Véase el resumen doctrinal que se hace en el FJ 4 a) de la STC 45/2019.

59 Con base en la jurisprudencia del TC, creo también que, como excepción, en circunstancias extraordinarias o de fuerza mayor, y siempre que se prevea en el reglamento parlamentario, se pueden celebrar sesiones parlamentarias telemáticas. No obstante, abierta la grieta de la excepción por el TC, me pregunto cuántas excepciones admite la presencialidad sin que esta se desnaturalice.

60 Art. 65 de la Ley 16/2003, de 28 de mayo, de cohesión y calidad del Sistema Nacional de Salud, reformado por el citado Decreto-Ley de nueva normalidad. Sobre el debate en torno al valor jurídico de las decisiones del CISNS, vid. el excelente comentario de Alvárez García, V., «El valor jurídico de las 
Era conocida (venía de antes) la polémica acerca de si la legislación sanitaria, en particular el famoso artículo 3 de la LOMESP ${ }^{61}$, habilitaba a las comunidades autónomas para adoptar medidas restrictivas de los derechos fundamentales de alcance general, en particular de la libertad de circulación. En lugar de modificar esa legislación, para darle la densidad normativa adecuada, el Gobierno prefirió impulsar la modificación de LJCA (llevada a cabo mediante Ley 3/2020, de 18 de septiembre). Por virtud de esta reforma se atribuyó a los Tribunales Superiores de Justicia de las Comunidades Autónomas la competencia para autorizar o ratificar las medidas de alcance general (las dirigidas a una pluralidad indeterminada de sujetos) que impliquen limitación o restricción de derechos fundamentales ${ }^{62}$. Con ello se daba a entender que la legislación sanitaria sí habilitaba a las comunidades autónomas para adoptar medidas de ese alcance.

Lejos de aclarar el panorama, la reforma de la LJCA lo oscureció. Ante el empeoramiento de las cifras de la pandemia, las comunidades autónomas empezaron a adoptar limitaciones severas de la libertad de circulación, a partir de los criterios establecidos por el CISNS, y las sometieron a ratificación. La actuación de los Tribunales Superiores de Justicia fue dispar: unos (la mayoría) ratificaron las medidas, otros (la minoría), no ${ }^{63}$. Había inseguridad jurídica. En estas circunstancias, el Gobierno decidió procurar un paraguas jurídico más seguro a las comunidades autónomas para limitar el ejercicio de derechos fundamentales. Ese paraguas jurídico fue el estado de alarma.

Mediante Real Decreto 926/2020, de 25 de octubre, se declaró el estado de alarma en todo el territorio nacional para contener la propagación del COVID19. En la exposición de motivos de mismo ya anunciaba el Gobierno su voluntad de prorrogarlo por seis meses, porque entendía que las medidas previstas deberían prolongarse en el tiempo, a la vista de la evolución esperada de la pandemia en los meses de invierno. La prórroga se autorizó por el Congreso de los Diputados el 29 de octubre de 2020 y se formalizó mediante Real Decreto 956/2020, de 3 de noviembre.

decisiones del Consejo Interterritorial del Sistema Nacional de Salud: la historia de un desencuentro institucional poco edificante», en www.aepda.es (entrada del 21-06-2021).

61 Ley Orgánica 3/1986, de 14 de abril, de Medidas Especiales en Materia de Salud Pública. El citado artículo dispone: «con el fin de controlar las enfermedades transmisibles ... la autoridad sanitaria ... podrá adoptar las medidas oportunas para el control de los enfermos, de las personas que estén o hayan estado en contacto con los mismos y del medio ambiente inmediato, así como las que se consideren necesarias en caso de riesgo de carácter transmisible».

62 Nuevo art. 11.1.i) LJCA. Si las medidas de alcance general provienen del Estado, la competencia recae en la Sala de lo contencioso-administrativo de la Audiencia Nacional [nuevo art. 10.8 LJCA]. Para las medidas de alcance individual, los competentes son los juzgados de lo contencioso administrativo [art. 8.6 LJCA].

63 El caso más sonado de no ratificación judicial fue el del auto del TSJ de la Comunidad de Madrid de 8 de octubre de 2020. El TSJ de Madrid no ratificó los confinamientos perimetrales adoptados por la Comunidad de Madrid mediante Orden 1273/2020, de 1 de octubre. Esa decisión judicial precipitó la declaración por el Gobierno del estado de alarma para determinados municipios de la Comunidad de Madrid (RD 900/2020, de 9 de octubre). 
En lo que hace a las medidas previstas, la declaración de estado de alarma es menos drástica que la anterior. No prevé ni el confinamiento general de toda la población ni la suspensión general de las actividades económicas en el sector servicios. En su lugar, prevé determinadas medidas restrictivas de la libertad de circulación $^{64}$. y, por otro, deja fuera del radio de acción de la alarma, pero dentro del radio de acción de la legislación sanitaria ordinaria, la adopción (por las comunidades autónomas) de medidas restrictivas de la actividad económica. No entraré en más consideraciones.

Para el propósito de este trabajo, me interesa recalcar dos novedades de la nueva declaración de alarma que tienen un indudable impacto sobre el control extraordinario que ejerce el Congreso. Me refiero a la prórroga por seis meses del estado de alarma y a la delegación en los Presidentes de las Comunidades Autónomas de la dirección de la alarma.

\section{b) La prórroga por seis meses del estado de alarma y el control por y en el Congreso}

El Gobierno tenía prisa por que se autorizara la prórroga del estado de alarma. Comunicó al Congreso la declaración del estado de alarma el 25 de octubre y, dos días después, la solicitud de autorización de la prórroga. El 29 de octubre compareció ante el Congreso, no el Presidente del Gobierno, sino el Ministro de Sanidad, para, al mismo tiempo, dar cuenta de la declaración de alarma y para solicitar su prórroga. Los grupos parlamentarios hicieron sus propuestas y, finalmente, se votaron estas (se aceptó una de ERC) y la prórroga. El resultado fue claro: 194 votos a favor (67 presenciales y el resto telemáticos), 53 en contra (todos telemáticos) y 99 abstenciones (25 presenciales y el resto telemáticos). Destaca que el principal partido de la oposición (el PP) se abstuviera.

La alarma decretada el 25 de octubre de 2020 fue prorrogada a su finalización (a las 00:00 horas del 9 de noviembre) por 6 meses (hasta las 00:00 del 9 de mayo de 2021) ¡Seis meses! ¿Es esto constitucional? Es verdad que el art. 116.2 $\mathrm{CE}$, así como fija la duración máxima de la declaración de alarma (15 días), nada dice expresamente sobre la duración máxima de la prórroga, a diferencia de lo que sucede con el estado de excepción (art. 116.3 CE). Ello puede dar pie a pensar que el Congreso es libre para fijar el plazo máximo de prórroga que considere oportuno, como lo es para fijar la duración del estado de sitio (art. 116.4 CE) ${ }^{65}$.

64 Limitación de la libertad circulación de las personas en horario nocturno (art. 5), de la entrada y salida en las comunidades autónomas y en las ciudades con Estatuto de Autonomía (art. 6) y de la permanencia de grupos de personas en espacios públicos y privados (art. 7). También la limitación de la permanencia de personas en lugares de culto (art. 8).

65 Es lo que sostiene, por ejemplo, García Roca. Tiende a pensar que las prohibiciones deben ser expresas, y no inferidas por juicios lógicos. En consecuencia: «No hay plazo legal y si la prórroga pasa a ser una disposición del Parlamento, la mayoría tiene discrecionalidad y el resultado plena legitimidad democrática» [GARCía RocA, J., «El control parlamentario y otros contrapesos del Gobierno en el estado de alarma: la 
Lógicamente, algún límite a la discrecionalidad del Congreso debería haber. Ese límite podría ser el que se deriva del artículo 1.2 LOAES: el tiempo estrictamente indispensable para asegurar el restablecimiento de la normalidad. Pero no dejaría de ser un límite inseguro.

Creo que hay buenas razones para sostener la inconstitucionalidad del plazo de seis meses. Cabe acudir a la literalidad del artículo 116.2 CE (interpretación literal ${ }^{66} \mathrm{o}$ a la misma lógica (interpretación lógica) ${ }^{67}$. Pero la razón más relevante es, a mi juicio, la teleológica: la finalidad del art. 116.2 CE. El estado de alarma prorrogado es un estado parlamentario. El sentido de la intervención del Congreso en la prórroga es que este decida periódicamente si las medidas continúan o no o si necesitan ser modificadas. Si la prórroga es larga, se desnaturaliza la capacidad de decisión que le CE atribuye al Congreso en garantía de la misma. Autorizando una prórroga de seis meses, el Congreso renuncia al ejercicio de una competencia propia que está obligado a ejercer, no puede renunciar a ella. En definitiva, la periodicidad corta (15 días) de la prórroga «no puede ser eliminada, ni siquiera por acuerdo de la propia Cámara, ya que es una garantía constitucional cuya vigencia no está a la libre disposición de la mayoría parlamentaria» ${ }^{68}$.

No solo el control extraordinario por el Congreso queda desnaturalizado con una prórroga de seis meses. También se resiente el control en el Congreso, pues se hurta a los parlamentarios o a los grupos parlamentarios su derecho al ejercicio periódico de participar en (formulando propuestas) y de debatir sobre el estado de alarma y sus medidas. En definitiva, se menoscaba a sus titulares el ius in officium protegido en el art. 23.2 CE y, por ende, el derecho de participación política de los ciudadanos ex art. 23.1 CE.

No basta para satisfacer el control por y en el Congreso que demanda el art. $116 \mathrm{CE}$ el que se exija en el art. 14 del decreto de alarma (modificado por el decreto de prórroga) una «rendición de cuentas» periódica del Presidente del Gobierno (cada dos meses) y del Ministro de Sanidad (cada mes). Una dación de cuentas, sin consecuencias jurídicas vinculantes para el Gobierno, es lo que se exige para el estado de alarma «gubernamental», que lo es del Gobierno porque decide sobre él. En el estado de alarma «parlamentario», la intervención del

experiencia del coronavirus», en BARceló Rojas, D., Díaz Ricci, S., García Roca, J. y Guimaraes Teixeira Rocha, M.E. (coords.), Covid 19 y parlamentarismo. Los Parlamentos en cuarentena, México, Universidad Autónoma de México, 2020, p. 25].

66 La expresión «dicho plazo» que emplea el art. 116.3 CE se refiere al plazo ya fijado para la declaración; y «prorrogarlo» significa, en principio, «repetirlo» y no «ampliarlo», salvo que el precepto constitucional lo hubiera dispuesto expresamente, cosa que no ha hecho [ARAgón Reyes, M.: «Epílogo», en Biglino Campos, P. y Durán AlBA, J.F. (dirs.), Los efectos horizontales de la Covid-19 sobre el sistema constitucional: estudios sobre la primera oleada, Zaragoza: Fundación Manuel Giménez Abad, colección obras colectivas, 18, 2021, p. 569].

67 La lógica dice que los plazos procesales (o procedimentales) no se prorrogan por un plazo superior al plazo original. Prueba constitucional al respecto: el art. 116.3 CE [RuIz Robledo, A.: «El estado de alarma: donde quiere el gobernante», El País, 6 de noviembre de 2020].

68 Aragón Reyes, M., «Covid y Estado autonómico», en Tudela Aranda, J. (coord.), Estado autonómico y Covid-19, Colección obras colectivas, Zaragoza: Fundación Manuel Giménez Abad, p. 11. 
Congreso no consiste en recibir una dación de cuentas del Gobierno, sino en decidir sobre la alarma. En el estado de alarma parlamentario, el Gobierno propone y el Congreso dispone ${ }^{69}$.

En fin, resulta notablemente perturbador lo que se dice en la Disposición Final Primera del Real Decreto de declaración del estado de alarma (RD 926/2020, de 25 de octubre): «durante la vigencia del estado de alarma» declarado por el citado Real Decreto, el Gobierno podrá dictar decretos «que modifiquen lo establecido en este», de acuerdo con lo previsto en el art. 8.2 de la LOAES. El RD 956/2020, de 3 de noviembre prorroga el estado de alarma declarado por el RD 926/2020, de 25 de octubre. Modifica determinados preceptos de este, pero nada dice respecto de la disposición final arriba citada (que no deroga) ¿Significa esto que durante la vigencia de la prórroga el Gobierno pudo modificar mediante decreto el contenido del decreto de alarma prorrogado, sin autorización previa del Congreso? Un «no» rotundo: esta es mi respuesta. Una vez autorizado la prórroga, cualquier modificación que pretenda hacer el Gobierno debe ser autorizada por el Congreso, al igual que sucede con el estado de excepción (art. 15.1 LOAES) ${ }^{70}$.

\section{c) La delegación autonómica del estado de alarma}

Con el estado de alarma decretado el 25 de octubre de 2020 y prorrogado por seis meses el 9 de noviembre, el Gobierno pretendía dotar de un paraguas jurídico a las comunidades autónomas. En ellas había descargado el Gobierno la

69 Una vez corregidas las (primeras) pruebas de este trabajo, se ha publicado en la página web del TC el adelanto de la parte dispositiva de la sentencia en la que resuelve el recurso de inconstitucionalidad presentado por 51 diputados del grupo parlamentario VOX del Congreso contra el Real Decreto 926/2020, la Resolución del Congreso por la que se autorizó la prórroga por seis meses del estado de alarma decretado en ese Real Decreto y el Real Decreto 956/2020, en el que se formaliza esa Resolución. Según se dice en la nota informativa $n .{ }^{\circ} 100 / 2021$, el Pleno declara inconstitucional la prórroga de los seis meses. Lo que merece la censura del Tribunal no es la duración de la prórroga, por sí sola y sin más, sino el carácter no razonable o infundado de la decisión parlamentaria por la que se fijó tal plazo. Reprocha también el TC el que las medidas que se autorizaban no iban a ser aplicadas inmediatamente por el Gobierno, pues su puesta en práctica se supeditaba a que los presidentes de las Comunidades Autónomas así lo decidieran. La autorización parlamentaria se dio así sin saber qué medidas se iban a aplicar para combatir la pandemia.

70 En la STC 148/2021, de 14 de julio, se dice lo siguiente: La LOAES «no excluye que las medidas originariamente incluidas en el decreto que declare la alama puedan ser modificadas por el propio Gobierno, tanto en el lapso de inicial vigencia de este estado de crisis como durante su eventual prórroga; siempre en el respeto, en esta última hipótesis, a lo autorizado por el Congreso de los Diputados» (FJ 9) ¿Qué quiere decir el TC? Modificar el decreto de alarma prorrogado es alterar el contenido del mismo. Ello supone, a mi juicio, no respetar lo autorizado por el Congreso de los Diputados y, por tanto, requiere una nueva autorización de éste. No basta con la mera comunicación ex art. 8.2 LOAES (exigible en el lapso inicial de vigencia de la alarma), es precisa una nueva autorización del Congreso.

Lo que sí puede hacer el Gobierno unilateralmente es levantar el estado de alarma antes del plazo señalado en la autorización. El plazo es máximo, no un plazo que obligatoriamente haya que agotar. Si el Gobierno logra restablecer la normalidad antes de tiempo, no solo puede, sino que debe poner fin al estado de alarma, dando cuenta al Congreso. Si no lo hiciera, incurriría en «un abuso de poder, inconciliable con la interdicción de la arbitrariedad (art. 9.3 CE)» [STC 148/2021, de 14 de julio, FJ 3 ii), (1)]. 
responsabilidad principal de la lucha contra la pandemia durante la «nueva normalidad» y en ellas descargará la responsabilidad con la nueva alarma.

El decreto de alarma prorrogado delega en las comunidades autónomas no solo la ejecución, sino la decisión de ejecutar las medidas de limitación de la libertad de circulación previstas en él. En el artículo 2 declara que la autoridad competente será el Gobierno de la Nación, pero, al mismo tiempo, por delegación, será autoridad competente (delegada) el presidente de la comunidad autónoma o ciudad con Estatuto de Autonomía en su respectivo territorio. Corresponde a las autoridades competentes delegadas decidir si aplicar o no las medidas previstas en su ámbito territorial (art. 9). No son, por tanto, medidas de eficacia inmediata, sino de eficacia condicionada a la voluntad de cada Presidente de comunidad o ciudad autónoma. Estos, además, pueden modular, flexibilizar e incluso suspender la aplicación de las medidas adoptadas (art. 10).

El estado de alarma pergeñado no es, en puridad, un estado de alarma. Son 19 potenciales estados de alarma (17 autonómicos y 2 de ciudades autónomas), cuya activación depende de la sola voluntad de las autoridades competente delegadas. Se trata de una delegación prácticamente en blanco, sujeta a un único y vago criterio: «a la vista de la evolución de los indicadores sanitarios, epidemiológicos, sociales, económicos y de movilidad» (art. 9), cuya interpretación queda en manos de la autoridad competente delegada. Es esta, pues, la que decide discrecionalmente, "previa comunicación al Ministerio de Sanidad y de acuerdo con lo previsto en el artículo 13» (art. 9). El artículo 13 atribuye al CISNS la coordinación de la aplicación de las medidas, que no de la decisión de aplicarlas. Ni el Ministro de Sanidad ni el CISNS pueden controlar previamente la decisión de la autoridad competente delegada. En fin, las medidas deben adoptarse, como mínimo, para siete días (art. 9).

No entro a valorar la eficacia en la lucha contra la pandemia de esta pluri-delegación de poderes. Desde luego, va en línea diametralmente opuesta a la lógica que preside los estados de emergencia: concentrar poderes en una instancia (el Ejecutivo) para hacer frente a una crisis (bajo control parlamentario). Mando único y estado de emergencia van de la mano. Me pregunto si es aceptable jurídicamente y mi respuesta es negativa. El decreto de alarma y su prórroga tienen que atenerse al marco definido por la ley orgánica a la que remite la CE, so pena de incurrir en inconstitucionalidad por infringir el art. $116.1 \mathrm{CE}^{71}$. Esa ley orgánica, la LOAES, solo permite que un Presidente de comunidad autónoma sea autoridad competente, por delegación del Gobierno, «cuando la declaración afecte exclusivamente a todo o parte del territorio de una comunidad autónoma» (art. 7 - la cursiva es mía). Esto significa, lisa y llanamente, que no cabe (pluri) delegación en los Presidentes autonómicos cuando la declaración afecte al territorio de más de una comunidad autónoma. Es el caso del estado de alarma declarado

71 Me sirvo de palabras de la STC 148/2021, de 14 de julio, FJ 3, ii) (2). 
el 25 de octubre de 2020 y prorrogado el 9 de noviembre por seis meses, que afectó a todo el territorio nacional (art. 3 del RD 926/2020, de 25 de octubre ${ }^{72}$.

La delegación de la alarma hace tenaza con la prórroga de seis meses para desdibujar el papel del Congreso. Si la alarma está en manos de los presidentes autonómicos, ellos son responsables de las medidas que adopten. El control parlamentario de las mismas se desplaza inevitablemente a los parlamentos autonómicos. El Congreso no pinta gran cosa. La rendición de cuentas del artículo 14 del decreto prorrogado pierde sentido ¿Qué cuentas se le pueden pedir al Gobierno de la nación, si este no es responsable de la ejecución de la alarma?

Sucede que los parlamentos autonómicos no cuentan con las armas del Congreso. No pueden decidir sobre la prórroga de las medidas de alarma adoptadas por los presidente autonómicos. Tampoco tienen asegurado el control político de las decisiones de estos determinando las medidas que adoptar y, en su caso, modulándolas, flexibilizándolas o suspendiéndolas. Esas decisiones se han adoptados mediante decretos del Presidente de la Comunidad Autónoma. Los presidentes autonómicos no están obligados jurídicamente a dar cuenta de sus decretos a sus parlamentos, a diferencia del Gobierno de la Nación (art. 8.2 LOAES) ${ }^{73}$. Si, durante la vigencia de alarma, han dado cuentas o no de ellos ha dependido de la eficacia de los instrumentos ordinarios de control parlamentario. Sabemos que estos, al igual que los de las Cortes Generales, están básicamente en manos de la mayoría. Es más, si la eficacia no caracteriza el ejercicio de la función de control político en el Congreso, menos lo hace en los Parlamentos autonómicos ${ }^{74}$.

\section{APUNTES FINALES}

1. Han quedado cosas en el tintero. Es inevitable, dada la limitación del espacio disponible. Pero no me resisto a apuntar (solo apuntar) algunas desviaciones de nuestra división de poderes que, en estos tiempos de pandemia, bien han emergido, bien se han agudizado. Ha emergido una desviación en la división horizontal de poderes: la conversión de los jueces en colegisladores o, para ser más

72 Así lo ha entendido también el TC. En nota informativa n. ${ }^{\circ}$ 100/2021, publicada en su página web, se adelanta la parte dispositiva de la sentencia en la que resuelve el recurso de inconstitucionalidad contra el estado de alarma decretado el 25 de octubre de 2020 y su prórroga (vid. nota 69). En ella se informa de que el Pleno del TC declara también inconstitucional el nombramiento de autoridades competentes delegadas. Entre otros motivos, se adelantan dos. El primero: la decisión contraviene lo dispuesto en la LOAES. El segundo: el Gobierno acordó con carácter permanente la delegación sin reserva alguna al mismo de la supervisión efectiva o la eventual avocación de lo que las autoridades delegadas pudieran hacer en sus respectivos ámbitos territoriales.

73 Tampoco a los jueces (art. 2.3 del RD 926/2020, de 25 de octubre).

74 Hago mías las palabras de Tudela Aranda. Añade el autor: «Distintas circunstancias lo explican. El mayor peso del ejecutivo y una aún más notable presidencialización de sistema; la, normalmente, mayor debilidad de la oposición; la carencia de medios materiales ... o la menor atención mediática» (Tudela ArANDA, J., «Parlamento y Estado de Alarma», en Garrido López, C. (coord.), Excepcionalidad y Derecho: el estado de alarma en España, Zaragoza: Fundación Manuel Giménez Abad, Colección Obras Colectivas, 2021, p. 30). 
exactos, en co-reglamentadores. Las medidas sanitarias de alcance general limitativas de derechos fundamentales necesitan de la voluntad de los jueces para surtir efectos: la autorización o ratificación judicial no es un acto de control, es una condición de eficacia de esas medidas ${ }^{75}$. Se ha agudizado otra desviación en la división horizontal de poderes: la conversión del Gobierno en legislador alternativo a las Cortes Generales. El decreto-ley, de excepción a la regla (la potestad legislativa la tienen las Cortes Generales), ha devenido en modo alternativo de legislar. La pandemia ha agudizado esta práctica desviada, que viene de lejos ${ }^{76}$. También ha agudizado una desviación en la división vertical del poder: el abandono del Estado de su función de coordinación, en manos de lo que se ha dado en llamar «cogobernanza». No es un secreto que la coordinación de la sanidad (competencia del

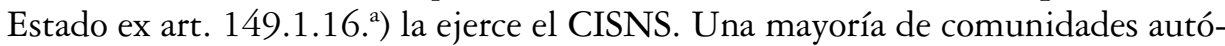
nomas puede imponer su voluntad al resto y el Estado se limita a formalizar esa voluntad, mediante Orden (no siempre publicada) ${ }^{77}$.

2. Nuestro Derecho de Excepción es garantista. Ofrece un control parlamentario (congresual) razonable a los poderes exorbitantes que los estados de emergencia ponen en manos del Ejecutivo. Ese control extraordinario se pudo ejercer en el primer estado de alarma, con dificultades, pero por problemas ajenos al Derecho, que este tuvo que resolver. La excepción a la presencialidad se arregló jurídicamente como se pudo. Sin embargo, en la segunda alarma quedó notablemente desnaturalizado, por causas directamente relacionadas con el Derecho, esto es, por la regulación llevada a cabo en el decreto de declaración y en el de su prórroga. No se trató del qué (las medidas) sino del cómo (la delegación en los Presidentes autonómicos y la prórroga por 6 meses). El estado de alarma regulado en esta segunda ocasión se desvía notablemente del diseñado por la CE y la LOAES.

3. El control parlamentario es más necesario que nunca en estos tiempos, porque nunca se ha dado en el Estado Constitucional una concentración tan elevada de poder en el Ejecutivo. Lo que está sucediendo con la pandemia lo corrobora. Es preciso mejorar las reglas jurídicas del control (la doctrina lleva clamando a ello desde hace tiempo). Pero no basta con ello. Es preciso también que funcionen las reglas políticas de la democracia parlamentaria. El Gobierno debe poder

75 No lo digo yo, lo dice el propio Tribunal Supremo [vid. FD 4 A) de la STS 719/2021, de 24 de mayo, Sala de lo Contencioso-administrativo, sección Cuarta]. Recuerdo al lector que el art. 15 del Real Decreto-Ley 8/2021, de 4 de mayo, introdujo la casación ante el TS contra los autos de los Tribunales Superiores de Justicia ex art. 11.1.j) LJCA y de la Audiencia Nacional ex art. 10.8 LJCA (nuevo art. art. 87.1 bis LJCA).

76 Especialmente con Gobiernos en minoría. En la XII Legislatura (la iniciada en julio de 2016 y finalizada en marzo de 2019), 37 decretos-leyes frente a 22 leyes. En esta legislatura (la XIV), 39 decretos-leyes solo en 2020 , frente a 14 leyes.

77 Esta desviación la auspicia el art. 151.2.a) de la Ley 40/2015, de 1 de julio, de Régimen Jurídico del Sector Público, en tanto dispone que los acuerdos adoptados por las Conferencias Sectoriales en ámbitos en los que el Estado ejerce funciones de coordinación (v.gr., sanidad) son de obligado cumplimiento para todas las comunidades autónomas, incluidas las que han no han votado a favor, y exigibles ante la jurisdicción contencioso-administrativa. 
gobernar (aunque esté en minoría), pero no debe obstaculizar el control por la oposición. Tampoco puede huir del Parlamento para eludir el control. Por su parte, la oposición debe controlar al Gobierno de verdad: su control debe ser útil y no meramente capilar y efectista. Y ese control debe hacerse en el lugar que corresponde, en el Parlamento, no solo (ni principalmente) en los medios de comunicación o en las redes sociales. Esto que digo es elemental, una obviedad, pero son tiempos difíciles, en los que hay que recordar lo que es obvio.

$$
* * *
$$

TITLE: Emergency law and parliamentary oversight

ABSTRACT: The purpose of this paper has been to analyze the parliamentary oversight in the Spanish emergency law. The first task has been to define the parliamentary oversight. Section I has dealt with it. The second task has been to delimit from a theoretical perspective the extraordinary parliamentary oversight (by and in) exercised by Congress in the Spanish Emergency Law. Section II has dealt with this. The third task has been to evaluate the extraordinary oversight exercised in practice by Congress in the two states of alarm decreed throughout the entire spanish territory to contain the COVID-19 pandemic. Section III has dealt with this. The paper ends with some brief final notes (Section IV).

RESUMEN: El propósito de este trabajo ha sido analizar el control parlamentario en nuestro Derecho de excepción. La primera tarea ha sido definir el control parlamentario. El epígrafe I se ha ocupado de ello. La segunda tarea ha sido delimitar desde una perspectiva teórica el control parlamentario extraordinario (por y en) que ejerce el Congreso en nuestro Derecho de excepción. El epígrafe II se ha ocupado de ello. La tercera tarea ha sido evaluar el control extraordinario ejercido en la práctica por el Congreso en los dos estados de alarma decretados en todo el territorio nacional para contener la pandemia del COVID-19. El epígrafe III se ha ocupado de ello. El trabajo finaliza con unos breves apuntes finales (epigrafe IV).

KEY WORDS: parliamentary oversight, emergency law, Spanish Congress, state of alarm.

Palabras Clave: control parlamentario, Derecho de excepción, Congreso de los Diputados, estado de alarma.

FECHA DE RECEPCIÓN: 26.07.2021

FECHA DE ACEPTACIÓN: 20.09.2021 